\title{
Functional Response of Healthy and Diseased Glomeruli to a Large, Protein-rich Meal
}

\author{
Alex Y. M. Chan, May-Ling L. Cheng, Lanny C. Keil,“ and Bryan D. Myers \\ Division of Nephrology, Department of Medicine, Stanford University Medical Center, Stanford, California 94305; \\ and *NASA-Ames Research Center, Moffett Field, California 94035
}

\begin{abstract}
Differential solute clearances and hormone assays were used to characterize the effect of a large, protein-rich meal $(1.5 \mathrm{~g} / \mathrm{kg})$ on glomerular function in 12 healthy volunteers (group $\mathrm{I}$ ) and 12 patients with chronic glomerular disease (group II). Changes from baseline during $3 \mathrm{~h}$ after the meal included an elevation of plasma osmolality, progressive urinary concentration, and increasingly positive fluid balance. Plasma renin activity and arginine vasopressin levels (measured in group II only) increased significantly. Nevertheless, the rate of peak postmeal renal plasma flow became elevated by 13 and $33 \%$ in groups I and II, respectively. Corresponding peak increases in postmeal glomerular filtration rate exceeded baseline by 10 and $16 \%$. In the proteinuric subjects of group II the fractional clearances of albumin, IgG and uncharged dextrans in the radius interval 36-54 $\AA$, declined significantly after the meal. A similar depression of the fractional dextran-clearance profile was observed also in group $I$. Applying the fractional clearances of relatively permeant dextrans (radii $\leq 44 \AA$ ) to a model of hindered solute transport through an isoporous membrane, we estimate that transmembrane hydraulic pressure difference increased by $12 \%$ in group I and by between 0 to $12 \%$ in group II after protein ingestion. We conclude (i) that oral protein ingestion increases glomerular ultrafiltration pressure and rate in both normal and diseased glomeruli, (ii) that this hemodynamic response may be mediated in part by the glomerulopressor hormones angiotensin II and arginine vasopressin, and (iii) that the foregoing hemodynamic changes exert no acute adverse effect on glomerular barrier size-selectivity.
\end{abstract}

\section{Introduction}

Since first recommended by Richard Bright in 1836, dietary protein restriction has been used to moderate progressive azotemia in patients with chronic renal disease (1). Recent evidence suggests that this salutory outcome is a consequence not only of reduced nitrogen retention, but also of an effect of low protein intake to ameliorate directly an underlying chronic glomerular injury. In the rat with a remnant kidney or diabetes mellitus, high levels of dietary protein intake have been associated invariably with accelerated glomerulosclerosis, increas-

Address correspondence to Dr. B. D. Myers, Division of Nephrology, Rm. S215, Stanford University School of Medicine, Stanford, CA 94305.

Received for publication 1 December 1986 and in revised form 24 August 1987.

J. Clin. Invest.

(c) The American Society for Clinical Investigation, Inc.

$0021-9738 / 88 / 01 / 0245 / 10 \quad \$ 2.00$

Volume 81 , January 1988, 245-254 ing proteinuria and a progressive decline in the GFR. In contrast, restricting dietary protein intake to low levels appears to protect rat glomeruli against both the structural and functional ravages of sclerosing glomerulopathy in the aforementioned circumstances $(2,3)$. Similar benefits of dietary protein restriction have accrued to patients with chronic glomerular diseases. Restricted protein intake has been shown to diminish markedly the level of proteinuria (4-6). Judged by long-term changes in serum creatinine concentration in such patients, a low protein diet has also attenuated a preexisting trend towards a progressive decline of GFR (7).

Nephron micropuncture of rats with a remnant kidney or insulin-treated diabetes mellitus has revealed a direct relationship between the level of dietary protein intake and the magnitude of glomerular perfusion rate and pressure $(2,3)$. This has led to the hypothesis that elevation of intracapillary glomerular pressures and/or flows leads to focal disruption of the filtration barrier, resulting in leakage of plasma proteins into Bowman's space (8). The enhanced transcapillary passage of protein macromolecules, in turn, has been postulated to initiate changes in mesangial function and structure, which lead ultimately to glomerulosclerosis (9).

A convincing link between dietary augmentation of capillary perfusion pressure and rate on the one hand, and barrier function on the other, remains to be demonstrated in the human glomerulus, however. Whereas lowering protein intake in patients with chronic glomerular disease has been shown to diminish urinary protein losses, neither GFR nor the renal plasma flow $(R P F)^{1}$ rate have fallen in parallel $(4,5)$. In an effort to elucidate more precisely a putative link between glomerular capillary perfusion characteristics and barrier function, we have studied proteinuric patients with diverse glomerular diseases before and after a large, protein-rich meal. We used the differential clearance of probe macromolecules of graded size in an attempt to simultaneously identify changes in glomerular ultrafiltration pressure and barrier size-selectivity. We also examined the effects of protein ingestion on two hormones that are known to have potent pressor activity in the glomerular microcirculation.

\section{Methods}

\section{Study population}

Three groups of subjects were examined. Group I was composed of 12 healthy volunteers who were consuming an ad libitum diet, and ranged in age from 19 to $51 \mathrm{yr}$, averaging $31 \pm 2 \mathrm{yr}($ mean \pm SEM). All denied a history of renal disease, diabetes, or hypertension, and were found at

1. Abbreviations used in this paper: $\mathrm{K}_{\mathrm{f}}$, glomerular ultrafiltration coefficient; $\Delta \mathrm{P}$, transcapillary hydraulic pressure difference; $\mathrm{PAH}$, paraaminohippuric acid; $\pi_{\mathrm{a}}$, afferent oncotic pressure; $\mathrm{r}_{\mathbf{0}}$, pore radius; $\mathrm{RPF}$, renal plasma flow. 
the time of examination to be normotensive and to have a negative dipstick test for urinary protein. Group II was composed of 12 patients with chronic glomerular disease and heavy proteinuria. The nature of their underlying glomerular disease was characterized by needle renal biopsy in all but one instance. The histopathological diagnoses were lupus-associated, proliferative glomerulonephritis $(n=4)$, idiopathic membrano-proliferative glomerulonephritis $(n=3)$, membranous glomerulopathy $(n=2)$, and one case each of minimal change and focal sclerosing glomerulopathy. The remaining patient has polycystic kidney disease. The patients ranged in age from 23 to $58 \mathrm{yr}$, averaging $45 \pm 3$ yr. A dietary history revealed their average daily protein and energy dietary intake to be $81 \pm 3 \mathrm{~g}$ and $1,740 \pm 16 \mathrm{kcal}$, respectively. Group III was composed of an additional 6 patients aged 24 to $54 \mathrm{yr}$ with proteinuria caused by focal sclerosing glomerulopathy $(n=3)$, membranous glomerulopathy $(n=2)$, and lupus-associated glomerulonephritis $(n=1)$. Unlike groups I and II, they were not given a protein-rich meal. Apart from a fasting state, however, their study protocol did not differ from that of group I and II subjects. They serve as a control group to examine the effects of the passage of time on the differential clearance of probe dextran macromolecules, and on circulating levels of the two pressor hormones of interest.

\section{Study protocol}

Antihypertensive and diuretic drugs were discontinued in all group II and III patients receiving such therapy $7 \mathrm{~d}$ before the study. Each patient and healthy volunteer was admitted to a clinical research center after an overnight $12-\mathrm{h}$ fast. The study protocol, approved previously by the institutional review board at Stanford University Medical Center, was described in detail, and informed consent to perform the study was obtained in each instance.

A priming infusion containing $10 \%$ inulin $(60 \mathrm{mg} / \mathrm{kg}), 20 \%$ paraaminohippuric acid (PAH, $8 \mathrm{mg} / \mathrm{kg})$, and $10 \%$ dextran $40(130 \mathrm{mg} / \mathrm{kg})$ was administered. Thereafter, inulin and PAH were infused continuously at a rate calculated to maintain their respective plasma concentrations constant at 20 and $1.5 \mathrm{mg} / \mathrm{dl}$. During a 60 -min equilibration period, a solution of $2.5 \%$ dextrose and $0.45 \%$ saline was infused at 20 (group I) or $12 \mathrm{ml} / \mathrm{kg}$ body wt (groups II and III) to promote a diuresis. Four accurately timed urine collections were then obtained by spontaneous voiding. Peripheral venous blood was drawn from an indwelling cannula to bracket each urine collection. The average inulin clearance for the four collection periods was equated with the GFR. RPF was calculated by dividing the corresponding PAH clearance by an estimate of the renal extraction ratio of PAH. In the healthy volunteers of group I, the renal PAH extraction ratio was assumed to be 0.85 (10, 11 ), whereas in group II and III subjects we assigned a corresponding value of 0.7 to allow for the depression of PAH extraction that has been observed previously by ourselves and others to attend proteinuric glomerular disease (12-16). ${ }^{2}$

The fractional clearances of test macromolecules, $\theta_{\mathrm{m}}$, were computed from urine and plasma of the first timed collection using the equation:

$\theta_{\mathrm{m}}=(U / P)_{m} /(U / P)_{i n}$,

where $(U / P)_{m}$ and $(U / P)_{i n}$ refer to the urine-to-midpoint plasma concentration ratios of test macromolecules (dextrans, albumin, and IgG) and of inulin, respectively.

Upon completion of the baseline clearances, the members of groups I and II ingested a large meal over a 30 -min period. The meal

2. Access to the renal vein during the course of a cardiac or inferior vena caval catheterization has permitted us to determine the renal PAH extraction ratio directly in 14 glomerulopathic patients. These patients had a histopathologic spectrum of glomerular disease and range of proteinuria similar to those in the group II subjects of the present study. We found the PAH extraction ratio to be depressed invariably. The range was from 0.48 to 0.79 , and the average value $0.67 \pm 0.06$. Our selection of 0.7 as a representative value for PAH extraction in group II subjects is based on the foregoing average value. contained $58.3 \mathrm{~g}$ of protein provided by eggs and a blended liquid composed of ProPac (Biosearch Medical Products Inc., Somerville, $\mathrm{NJ}$ ) and chocolate milk. Additional protein was given as a weighed portion of tenderloin steak calculated to provide each subject with a total of $1.5 \mathrm{~g}$ protein $/ \mathrm{kg}$ body wt. The total amounts of protein and other dietary constituents consumed were similar in the two groups and are summarized in Table $I$.

Upon completion of the test meal, clearance collections were repeated at 30-min intervals over a 3-h period. An attempt was made to replace urinary losses quantitatively throughout the baseline, test meal, and postmeal periods by infusing a $2.5 \%$ dextrose and $0.45 \%$ sodium chloride solution during each 30 -min interval in an amount equal to the urinary output of the preceding $30 \mathrm{~min}$. Changes in plasma volume, $\Delta V$, from baseline were calculated from the hourly fractional hematocrit, $H c t$, using the equation:

$\Delta V=\left[1 /\left(1-H c t_{1}\right)\right] \times\left[\left(H c t_{1}-H c t_{2}\right) / H c t_{2}\right] \times 100$,

where $H c t_{1}$ is the baseline value and $H c t_{2}$, subsequent values after ingestion of the test meal. The mean arterial blood pressure (calculated as diastolic pressure plus one-third of the pulse pressure) and plasma oncotic pressure, together with serum and corresponding urinary concentrations of total solute and sodium, were measured along with the hematocrit during the baseline, and again at hourly intervals after the test meal. Plasma renin activity (in groups I and II) and arginine vasopressin levels (group II only) were also determined at the same hourly intervals. The effect of the test meal on barrier function was examined by remeasuring the concentrations of dextran, albumin, and IgG in samples of urine and plasma from the third postmeal hour, a period that coincided usually with the peak GFR after the test meal. To permit changes in hormonal levels and fractional dextran clearances to be attributed unequivocally to the test meal, these measurements were repeated at timed intervals corresponding to those of groups I and II in the fasting members of group III.

\section{Laboratory procedures}

\section{EXOGENOUS MARKERS}

Plasma and urinary concentrations of inulin and PAH were analyzed using techniques that have been described previously (17). Separation of dextran 40 in protein-free filtrates of plasma and urine into narrow fractions was achieved by high performance liquid chromatography using a pump (2010; Varian Associates, Inc., Palo Alto, CA) and two Micropak TSK columns in series (SW 3000 and SW 4000; Toyosoda, Tokyo, Japan). The columns were calibrated with three narrowly dispersed dextrans and an inulin preparation, all of known molecular weight $(70,40,10$ and $5.5 \mathrm{kD}$, respectively). Blue dextran was used to identify the void volume. Dextran concentration was measured using an "on-line" refractive index detector (RS-3; Varian Associates, Inc.). An integrator (4270; Spectra-Physics, Inc., Mountain View, CA) was used to divide the chromatogram into four slices per minute at a chart speed of $0.25 \mathrm{~cm} / \mathrm{min}$ during the 30 -min run. The integrated area of each slice was equated with the dextran concentration at the corre-

Table I. Composition of Test Meal

\begin{tabular}{lcc}
\hline & Group I & Group II \\
\hline Weight $(k g)$ & $80 \pm 1$ & $70 \pm 2$ \\
Sodium $(m g)$ & $897 \pm 23$ & $886 \pm 9$ \\
Potassium $(m g)$ & $1,682 \pm 67$ & $1,540 \pm 76$ \\
Phosphate $(m g)$ & $1,208 \pm 25$ & $1,141 \pm 38$ \\
Protein $(g)$ & $120 \pm 6$ & $105 \pm 5$ \\
Fat $(g)$ & $68 \pm 2$ & $64 \pm 2$ \\
Carbohydrate $(g)$ & $68 \pm 0$ & $68 \pm 0$ \\
Energy $(k c a l)$ & $1,364 \pm 15$ & $1,288 \pm 25$
\end{tabular}


sponding retention time. Molecular radius, $r_{s}$, was computed from the linear relationship between retention time and molecular weight, $M W$, where

$r_{s}=0.33 \times(M W)^{0.463}$.

The fractional clearances of each discrete dextran fraction at $2-\AA$ intervals over the molecular radius range, $30-54 \AA$, were computed using Eq. 1.

\section{ENDOGENOUS MARKERS}

A rate-dependent modification of the Jaffe reaction that minimizes the influence of slow-reacting, noncreatinine chromogens was used to measure true creatinine concentration in plasma and urine. Total solute concentration in urine and plasma was measured with an osmometer, whereas corresponding sodium concentrations were determined by flame photometry. Plasma concentrations of albumin and IgG were determined by radial immunodiffusion, as described previously (17). The concentrations of albumin in unconcentrated urine of all, and of urinary IgG in all, but three group II patients with glomerular disease were determined also by radial immunodiffusion using low level plates (Kallestad Laboratories, Inc., Austin, TX). Albumin and IgG concentrations in unconcentrated urine of normal volunteers, and corresponding IgG concentrations in the three remaining group II patients with glomerular disease were unmeasurable by radial immunodiffusion, however. These concentrations were determined instead by a sensitive enzyme-linked immunosorbent assay. Oncotic pressure of plasma was determined directly using a membrane osmemeter (IL Weil Oncometer-TM, Lexington, MA).

\section{HORMONE ASSAYS}

For determination of hormone levels in plasma, blood was collected into chilled, heparinized tubes containing disodium ethylenediamine tetra acetate and aprotinin, and stored at $-70^{\circ} \mathrm{C}$ until the day of radioimmunoassay. Plasma renin activity was measured as the rate of immunoassayable angiotensin I generated in plasma incubated at $\mathrm{pH}$ 7.4 and $37^{\circ} \mathrm{C} \mathrm{(18).} \mathrm{Arginine} \mathrm{vasopressin} \mathrm{levels} \mathrm{in} \mathrm{plasma} \mathrm{were} \mathrm{deter-}$ mined after an extraction and radioimmunoassay procedure that has been described in detail previously (19).

\section{Theoretical analysis of glomerular transcapillary water and solute flux}

The inert and uncharged polysaccharides, inulin and dextran, are excreted solely by glomerular filtration and neither secreted nor reabsorbed by the tubule $(20,21)$. The urinary clearance of a dextran of given size relative to inulin, therefore, reflects its Bowman's space-toplasma concentration ratio or sieving coefficient. For relatively permeant dextrans (radius $\leq 44 \AA$ ), the glomerular capillary wall can be represented to reasonable approximation as an isoporous membrane, one perforated by cylindrical pores of identical radius $\left(r_{0}\right)(22)$. It has been shown, however, that transmembrane dextran flux is governed not only by $\mathbf{r}_{0}$, but also by the glomerular ultrafiltration coefficient $\left(K_{f}\right)$ and the three hemodynamic determinants of GFR, namely the afferent oncotic pressure $\left(\pi_{\mathrm{a}}\right), \mathrm{RPF}$ rate, and transcapillary hydraulic pressure difference $(\Delta P)(22,23)$.

As stated previously, $\Delta \mathrm{P}$ has been shown in the rat to vary with the level of dietary protein intake $(2,3)$. To examine whether this is true also of man, we assigned to $\Delta \mathrm{P}$ an arbitrary baseline value consistent with a state of mild filtration pressure disequilibrium. We then used a theoretical model of hindered solute transport through an isoporous membrane to predict the effects on dextran sieving coefficients of hypothetical increases in $\Delta \mathrm{P}$ above the arbitrary baseline after ingestion of the test meal. The model includes mass balance relations that predict variations in concentrations and fluxes of the probe dextran macromolecules along the length of the glomerular capillary $(22,23)$. It becomes possible therefore to predict approximately the effect on postmeal dextran sieving coefficients of a hypothetical elevation of $\Delta \mathrm{P}$, while taking into account the influence on convective and diffusive transmembrane dextran transport of simultaneous changes in GFR,
$\mathrm{RPF}$, and $\pi_{\mathrm{a}}$. Comparison of these predictions to the observed alteration from baseline values of the dextran sieving coefficients then provides an indirect means of assessing the likelihood of an effect of protein ingestion to elevate $\Delta P$.

\section{Statistical analysis}

Intergroup differences between glomerulopathic patients and healthy volunteers, and intragroup differences between baseline conditions and the postprandial state were evaluated with an analysis of variance using the CLINFO system. Differences were regarded as significant when $P<0.05$. All results are expressed as means \pm one standard error.

\section{Results}

\section{Excretory response}

The excretory response to the protein-rich meal is summarized in Table II. The intravenous infusion of $2.5 \%$ dextrose and $0.45 \%$ saline used to induce diuresis in normal subjects of group I $(20 \mathrm{ml} / \mathrm{kg})$ resulted in a positive balance of fluid and sodium by the end of the baseline clearance period, 1,448 \pm 142 $\mathrm{ml}$ and $193 \pm 18 \mathrm{meq}$, respectively. Despite attempts at precise replacement, fluid and sodium balance became more positive postmeal, increasing eventually to $1,636 \pm 111 \mathrm{ml}$ and $206 \pm 19$ meq. A similar pattern of increasingly positive fluid and sodium balance was observed in the patients with glomerular disease (group II), peaking at $1,075 \pm 114 \mathrm{ml}$ and $130 \pm 14 \mathrm{meq}$ by the end of the third postmeal hour (Table II, bottom). Despite the positive fluid balance, the meal had a marked antidiuretic effect. Urine flow rate declined by $>50 \%$ in both groups, reflecting progressive postmeal concentration of an initially dilute urine. The urine-to-plasma osmolality ratio increased from $0.29 \pm 0.02$ and $0.55 \pm 0.07$ to exceed unity in the second and third postmeal hours, peaking at $1.62 \pm 0.15$ and $1.26 \pm 0.18$ in the third hour in groups I and II, respectively. The corresponding fractional excretion of sodium became elevated in parallel in group I subjects, increasing from $2.4 \pm 0.4$ at baseline to $3.2 \pm 0.3 \%$ during the third postmeal hour. In contrast, postmeal fractional sodium excretion declined below baseline $(3.6 \pm 0.8 \%)$ in group II patients, falling significantly in the first postmeal hour $(2.1 \pm 0.5 \%)$, and returning slowly towards baseline thereafter.

\section{Hormonal response}

Changes in plasma volume, total solute concentration, and hormonal levels after the meal are summarized in Table III. From Eq. 2 and a significant decline in hematocrit in the third postmeal hour, we estimate that plasma volume became expanded at this time in both group I $(2.5 \pm 0.9 \%)$ and II subjects $(2.0 \pm 1.0 \%)$. Despite increasingly positive sodium balance and an expanding plasma volume, mean plasma renin activity was elevated above baseline at all times after the meal; the elevation reached statistical significance in both groups in the first hour. Plasma arginine vasopressin levels were measured in group II patients with glomerular disease only. Although initially low after the half-normal saline and dextrose prime, plasma arginine vasopressin increased from a baseline value of $0.78 \pm 0.23$ to a peak value of $1.43 \pm 0.28 \mathrm{pg} / \mathrm{ml}$ in the third hour after the meal $(P=0.02)$. This late rise appeared to follow a small but significant $(P<0.05)$ postabsorptive increase by $1.6 \mathrm{mosmol} / \mathrm{kg} \mathrm{H}_{2} \mathrm{O}$ and $1.8 \mathrm{meq} / \mathrm{liter}$ of serum total solute and sodium concentrations, respectively. Corresponding increases of similar magnitude in group I subjects (Table III) 


\begin{tabular}{|c|c|c|c|c|c|}
\hline & \multicolumn{2}{|c|}{ Cumulative balance } & \multirow[b]{2}{*}{ Urine flow } & \multirow{2}{*}{$\begin{array}{l}\mathrm{U} / \mathrm{P} \\
\text { osmolality }\end{array}$} & \multirow[b]{2}{*}{$\mathrm{FE}_{\mathrm{Na}}$} \\
\hline & Fluid & Sodium & & & \\
\hline & $m l$ & meq & $\mathrm{ml} / \mathrm{min}$ & & $\%$ \\
\hline \multicolumn{6}{|l|}{ Group I } \\
\hline Baseline & $1,448 \pm 142$ & $193 \pm 18$ & $16.8 \pm 1.6$ & $0.29 \pm 0.02$ & $2.4 \pm 0.4$ \\
\hline \multicolumn{6}{|l|}{ Postmeal } \\
\hline hour 1 & $1,565 \pm 137$ & $206 \pm 19^{*}$ & $5.8 \pm 0.9^{*}$ & $1.04 \pm 0.19^{*}$ & $2.2 \pm 0.3$ \\
\hline hour 2 & $1,650 \pm 115^{*}$ & $215 \pm 19^{*}$ & $4.8 \pm 0.9^{*}$ & $1.39 \pm 0.16^{*}$ & $2.9 \pm 0.3$ \\
\hline hour 3 & $1,636 \pm 111^{*}$ & $206 \pm 19 *$ & $4.5 \pm 0.8^{*}$ & $1.62 \pm 0.15^{*}$ & $3.2 \pm 0.3^{*}$ \\
\hline Peak hour change (\%) & +14 & +11 & -73 & +459 & +35 \\
\hline \multicolumn{6}{|l|}{ Group II } \\
\hline $\begin{array}{l}\text { Baseline } \\
\text { postmeal }\end{array}$ & $951 \pm 104$ & $105 \pm 12$ & $6.1 \pm 0.9^{\ddagger}$ & $0.55 \pm 0.07^{\ddagger}$ & $3.6 \pm 0.8$ \\
\hline hour 1 & $983 \pm 108$ & $111 \pm 13^{*}$ & $3.2 \pm 0.6^{*}$ & $0.87 \pm 0.11^{*}$ & $2.1 \pm 0.5^{*}$ \\
\hline hour 2 & $1,067 \pm 127^{*}$ & $127 \pm 14^{*}$ & $2.1 \pm 0.2^{*}$ & $1.25 \pm 0.16^{*}$ & $2.7 \pm 0.8$ \\
\hline hour 3 & $1,075 \pm 114^{*}$ & $130 \pm 14^{*}$ & $2.5 \pm 0.5^{*}$ & $1.26 \pm 0.18^{*}$ & $2.8 \pm 0.6$ \\
\hline Peak hour change (\%) & +13 & +24 & -66 & +129 & -42 \\
\hline
\end{tabular}

$\mathrm{U} / \mathrm{P}$, urine-to-plasma ratio; $\mathrm{FE}_{\mathrm{Na}}$, fractional sodium excretion. ${ }^{*} P<0.05$ postmeal vs. baseline. ${ }^{\ddagger} P<0.05$ baseline of group II vs. baseline of group I.

could have provided an osmotic stimulus to arginine vasopressin release, and thus explain the striking increase in urinary concentration observed in this group.

In contrast to groups I and II, neither plasma renin activity nor arginine vasopressin levels increased with the passage of time in the fasting subjects of group III. Plasma renin activity remained constant during the three consecutive hours after the baseline clearance, averaging $2.01 \pm 0.90,2.10 \pm 0.98$, and $2.06 \pm 0.99 \mathrm{ng} / \mathrm{ml}$ per $\mathrm{h}$, respectively, vs. an initial value of $2.98 \pm 1.36 \mathrm{ng} / \mathrm{ml}$ per $\mathrm{h}(P=\mathrm{NS})$. Corresponding postbaseline values for arginine vasopressin were $1.97 \pm 0.26,1.42 \pm 0.47$, and $1.88 \pm 0.25 \mathrm{pg} / \mathrm{ml}$, respectively, vs. a baseline level of
$1.85 \pm 0.46 \mathrm{pg} / \mathrm{ml}(P=\mathrm{NS})$. Thus, neither the infusion of clearance markers nor fluid loading and the replacement of urinary losses can explain the observed elevation of circulating levels of renin and arginine vasopressin after protein ingestion.

\section{Glomerular functional response}

The effects of the test meal on glomerular function are summarized in Table IV. Mean arterial pressure declined only slightly by 1-2 $\mathrm{mm} \mathrm{Hg}$ in the normal subjects of group I, but fell more markedly and significantly in group II subjects with glomerular disease, from $106 \pm 5$ to $100 \pm 4 \mathrm{~mm} \mathrm{Hg}(P<0.05)$. Notwithstanding a tendency to hypotension, RPF became ele-

Table III. Hormonal Response

\begin{tabular}{|c|c|c|c|c|c|}
\hline . & $\Delta \mathbf{V}$ & Serum osmolality & Serum sodium & PRA & AVP \\
\hline & $\%$ & $\mathrm{mosmol} / \mathrm{kg} \mathrm{H}_{2} \mathrm{O}$ & meq/liter & $n g / m l$ per $h$ & $p g / m l$ \\
\hline \multicolumn{6}{|l|}{ Group I } \\
\hline Baseline & - & $287.5 \pm 2.4$ & $138.6 \pm 1.0$ & $0.27 \pm 0.02$ & ND \\
\hline \multicolumn{6}{|l|}{ Postmeal } \\
\hline hour 1 & $0.3 \pm 1.2$ & $288.1 \pm 2.2$ & $139.8 \pm 0.8$ & $0.36 \pm 0.05^{*}$ & ND \\
\hline hour 2 & $2.1 \pm 1.7$ & $288.3 \pm 1.2$ & $139.8 \pm 0.7$ & $0.93 \pm 0.45$ & ND \\
\hline hour 3 & $2.5 \pm 0.9^{*}$ & $290.0 \pm 2.2^{*}$ & $140.0 \pm 0.6$ & $0.45 \pm 0.15$ & ND \\
\hline Peak hour change (\%) & +2.5 & +1 & +1 & +244 & \\
\hline \multicolumn{6}{|l|}{ Group II } \\
\hline Baseline & - & $283.7 \pm 2.0$ & $138.3 \pm 1.1$ & $0.71 \pm 0.14^{\ddagger}$ & $0.78 \pm 0.23$ \\
\hline \multicolumn{6}{|l|}{ Postmeal } \\
\hline hour 1 & $-1.1 \pm 1.3$ & $283.3 \pm 2.4$ & $138.9 \pm 1.2$ & $1.17 \pm 0.31^{*}$ & $0.84 \pm 0.18$ \\
\hline hour 2 & $-0.5 \pm 0.9$ & $285.3 \pm 2.0^{*}$ & $140.1 \pm 1.0^{*}$ & $1.10 \pm 0.26$ & $0.95 \pm 0.23$ \\
\hline hour 3 & $2.0 \pm 1.0^{*}$ & $284.7 \pm 2.6$ & $139.6 \pm 0.9$ & $1.71 \pm 0.92$ & $1.43 \pm 0.28^{*}$ \\
\hline Peak hour change (\%) & +2.0 & +1 & +1 & +141 & +82 \\
\hline
\end{tabular}

$\Delta \mathrm{V}$, change in plasma volume; PRA, plasma renin activity; AVP, plasma arginine vasopressin. ${ }^{*} P<0.05$ postmeal vs. baseline. ${ }^{\ddagger} P<0.05$ baseline of group I vs. baseline of group II. 
Table IV. Glomerular Functional Response

\begin{tabular}{|c|c|c|c|c|c|c|c|c|c|c|}
\hline & GFR & RPF & FF & MAP & $\pi_{n}$ & $\mathbf{U V}_{\mathbf{a l b}}$ & $\mathbf{U V}_{\mathbf{l} \mathbf{G}}$ & $\theta_{\text {sab }}$ & $\theta_{100}$ & $\theta_{\mathrm{Cr}}$ \\
\hline & \multicolumn{3}{|c|}{$\mathrm{ml} / \mathrm{min}$ per $1.73 \mathrm{~m}^{2}$} & $m m H g$ & $m m H g$ & $\mu g / \min$ & $\mu g / \min$ & $\times 10^{-5}$ & $\times 10^{-5}$ & \\
\hline \multicolumn{11}{|l|}{ Group I } \\
\hline Baseline & $101 \pm 4$ & $573 \pm 47$ & $0.19 \pm 0.02$ & $88 \pm 2$ & $20.8 \pm 0.4$ & $3.8 \pm 0.6$ & $1.2 \pm 0.2$ & $0.8 \pm 0.1$ & $1.2 \pm 0.2$ & $1.21 \pm 0.04$ \\
\hline \multicolumn{11}{|l|}{ Postmeal } \\
\hline hour 1 & $106 \pm 4$ & $624 \pm 32$ & $0.17 \pm 0.01$ & $86 \pm 2$ & $20.9 \pm 0.4$ & - & - & - & - & $1.19 \pm 0.05$ \\
\hline hour 2 & $108 \pm 4^{*}$ & $646 \pm 31$ & $0.17 \pm 0.01$ & $87 \pm 1$ & $20.3 \pm 0.4$ & - & - & - & - & $1.21 \pm 0.04$ \\
\hline hour 3 & $111 \pm 4^{*}$ & $629 \pm 33$ & $0.18 \pm 0.01$ & $87 \pm 2$ & $19.9 \pm 0.3$ & $3.8 \pm 0.5$ & $1.6 \pm 0.2^{*}$ & $0.7 \pm 0.1$ & $1.3 \pm 0.1$ & $1.16 \pm 0.03$ \\
\hline Peak hour change (\%) & +10 & +13 & -10 & -2 & -4 & +1 & +28 & -13 & +6 & -4 \\
\hline \multicolumn{11}{|l|}{ Group II } \\
\hline Baseline & $53 \pm 8^{\ddagger}$ & $452 \pm 86$ & $0.14 \pm 0.02$ & $106 \pm 5^{\ddagger}$ & $17.5 \pm 1.5^{\ddagger}$ & $1,543 \pm 402^{\ddagger}$ & $133 \pm 45^{\ddagger}$ & $218 \pm 80^{\ddagger}$ & $63 \pm 24^{\ddagger}$ & $1.62 \pm 0.09^{\ddagger}$ \\
\hline \multicolumn{11}{|l|}{ Postmeal } \\
\hline hour 1 & $56 \pm 9$ & $552 \pm 95$ & $0.11 \pm 0.01$ & $103 \pm 4$ & $17.2 \pm 1.4$ & - & - & - & - & $1.67 \pm 0.09$ \\
\hline hour 2 & $57 \pm 8$ & $562 \pm 93^{*}$ & $0.11 \pm 0.01$ & $100 \pm 4^{*}$ & $16.8 \pm 1.4^{*}$ & - & - & - & - & $1.52 \pm 0.07$ \\
\hline hour 3 & $61 \pm 9^{*}$ & $589 \pm 104^{*}$ & $0.12 \pm 0.01$ & $101 \pm 4$ & $16.7 \pm 1.4^{*}$ & $1,684 \pm 388$ & $117 \pm 34$ & $171 \pm 57^{*}$ & $40 \pm 13^{*}$ & $1.48 \pm 0.06$ \\
\hline Peak hour change $(\%)$ & +16 & +33 & -21 & -6 & -5 & +9 & -12 & -22 & -35 & -9 \\
\hline
\end{tabular}

FF, filtration fraction; UV, urinary excretion rate; $\theta$, fractional clearance. ${ }^{*} P<0.05$ postmeal vs. baseline. ${ }^{\ddagger} P<0.05$ baseline of group I vs. baseline of group II.

vated in the wake of the test meal. The peak elevation was most marked in group II subjects, reflecting an increase above baseline of $33 \%$, from $452 \pm 86$ to $589 \pm 104 \mathrm{ml} / \mathrm{min}$ per $1.73 \mathrm{~m}^{2}$ $(P<0.01)$. The corresponding elevation of RPF in group I was from $573 \pm 47$ to $646 \pm 31 \mathrm{ml} / \mathrm{min}$ per $1.73 \mathrm{~m}^{2}$, an increase of only $13 \%$ that failed narrowly to achieve statistical significance $(P=0.1)$. GFR in each group rose in parallel; an increase by $16 \%$ in group II was again larger than a corresponding $10 \%$ increase in group I. The increase in GFR could be attributed not only to higher RPF, but also to a lower $\pi_{\mathrm{a}}$. Reflecting hemodilution of plasma proteins in the postmeal volume-expanded state, $\pi_{\mathrm{a}}$ declined, reaching a nadir value $0.9(P=0.07)$ and $0.8 \mathrm{~mm} \mathrm{Hg}(P<0.005)$ below baseline in groups I and II, respectively.

The peak postmeal GFR and RPF in individual group II subjects are examined as a function of the corresponding baseline values in Fig. 1. As shown, each lies above the line of identity, indicating both quantities to have increased invariably after the large, protein-rich meal. Linear regression analysis reveals a higher coefficient of correlation between the peak and baseline levels of GFR than RPF, 0.98 vs. 0.87 , respectively. The slope of the regression line for peak vs. baseline GFR suggests that the magnitude of the GFR increment
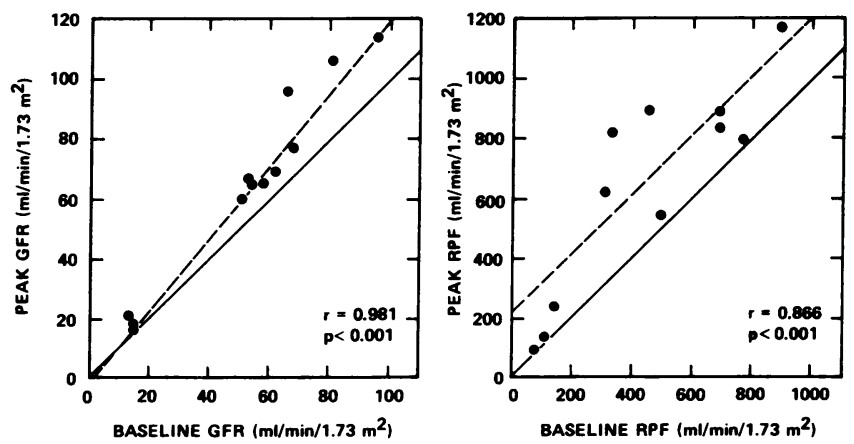

Figure 1. Peak postmeal GFR (left) and RPF (right) are plotted as a function of the corresponding baseline values. The solid line is the line of identity. The slope of the regression line (dashed) has been derived by linear regression analysis. achieved after the meal in this group is related directly to the initial GFR. Reflecting the weaker correlation, the relationship between peak and baseline RPF was less predictable, suggesting that the postmeal RPF increment may be independent of the baseline value. Whereas group II subjects exhibited a broad range of initial values for GFR and RPF (Fig. 1), the corresponding values were narrowly distributed in normal group I subjects. As a result, no relationship was discernible between the peak and baseline values of either RPF or GFR (coefficients of correlation of 0.02 and 0.22 , respectively).

As may be seen in Table IV (last column), the fractional clearance of creatinine was significantly higher in group II than in group I subjects, reflecting enhanced fractional secretion of creatinine by the tubules in the former. Coincident with peak GFR in the third postmeal hour, however, there was a numerical reduction of fractional creatinine clearance by 4 and $9 \%$ in groups I and II, respectively, with the latter reduction approaching statistical significance $(P=0.06)$. That the large contribution of tubular secretion to urinary creatinine clearance may obscure the magnitude of the postmeal increment in GFR in group II subjects, is illustrated by the data in Table V. Because the creatinine glomerular clearance is taken to be identical to that of inulin, subtracting the inulin clearance from the simultaneous clearance of creatinine reveals the creatinine tubular clearance of group II subjects to have remained constant at $26 \mathrm{ml} / \mathrm{min}$, both before and in the third hour after the meal. Put another way, the percentage of secreted-to-filtered creatinine fell from $62 \pm 9 \%$ in the fasting state to $48 \pm 6 \%$ at the time of the peak GFR increment in the third postmeal hour, a decline that failed only narrowly to achieve statistical significance $(P=0.07)$. The disparate effects of protein ingestion on GFR and tubular creatinine secretion in group II subjects limit the percentage increase in postprandial creatinine clearance to only $5 \%$, when in reality the true GFR increased by $16 \%$ (Table V). Thus, the widespread use of creatinine clearance to estimate the GFR may explain the discrepancy between the present findings and earlier reports that postprandial GFR rises proportionately less in patients with glomerular disease than in normal subjects (24-26).

The respective excretion rates of albumin and $\operatorname{IgG}(3.8 \pm 0.6$ and $1.2 \pm 0.2 \mu \mathrm{g} / \mathrm{min}$ in group I controls) were massively en- 
Table V. Creatinine Handling in Glomerular Disease

\begin{tabular}{lll}
\hline & Baseline & Postmeal hour 3 \\
\hline $\begin{array}{l}\text { Inulin clearance }(\mathrm{ml} / \mathrm{min} \text { per } \\
\left.1.73 \mathrm{~m}^{2}\right)\end{array}$ & $53 \pm 8$ & $61 \pm 9^{*}$ \\
$\begin{array}{l}\text { Creatinine clearance }(\mathrm{ml} / \mathrm{min} \text { per } \\
\left.\quad 1.73 \mathrm{~m}^{2}\right)\end{array}$ & $86 \pm 13$ & $90 \pm 13$ \\
$\begin{array}{l}\text { Creatinine tubular clearance } \\
\left(m l / m i n \text { per } 1.73 \mathrm{~m}^{2}\right)\end{array}$ & $26 \pm 3$ & $26 \pm 5$ \\
$\begin{array}{l}\text { Creatinine tubular-to-glomerular } \\
\text { clearance }(\%)\end{array}$ & $62 \pm 9$ & $48 \pm 6^{\ddagger}$ \\
\hline
\end{tabular}

${ }^{*} P<0.05$ postmeal vs. baseline.

$\ddagger 0.05<P<0.1$ postmeal vs. baseline.

hanced in group II subjects, averaging $1,543 \pm 402$ and $133 \pm 45$ $\mu \mathrm{g} / \mathrm{min}$ under baseline conditions. With the exception of a small increase to $1.6 \pm 0.2 \mu \mathrm{g} / \mathrm{min}$ of IgG excretion in group I, there was no significant change in urinary protein excretion rate after the meal (Table IV). However, micropuncture studies in the rat have revealed that at the high filtered loads observed in group II subjects, the fraction of filtered protein taken up by endocytosis into proximal tubular cells is minor (27). If this is true also for man, the fractional clearance of each protein should approach its sieving coefficient under these circumstances. Note, therefore, that both the fractional clearances of albumin (from [218 580$] \times 10^{-5}$ to $[171 \pm 57] \times 10^{-5}$, $P<0.05$ ) and $\mathrm{IgG}$ (from $[63 \pm 24] \times 10^{-5}$ to $[40 \pm 13] \times 10^{-5}, P$ $<0.05$ ) declined after the meal.

There was also a uniform depression of the sieving coefficients of dextrans of broad size distribution (Table VI). Comparison with baseline is limited to dextrans of radius $\geq 36 \AA$ because smaller constituent molecules of the dextran 40 infusate had been largely excreted by the third hour after the meal. Nevertheless, over the entire molecular radius range that remained measurable, postmeal dextran sieving coefficients were significantly depressed below baseline values in both groups (Table VI). The comparable magnitude of depression of transmembrane passage of large, relatively impermeant (radius $\geq 50 \AA$ ) and smaller, permeant dextrans suggests that ingesting a large, protein-rich meal has no acute, deleterious effects on barrier size-selectivity (17).

In contrast to the subjects of groups I and II, the passage of time alone had no discernable effect on fractional dextran clearances in the fasting subjects of group III (Table VII). Over the radius interval measurable in the fifth hour after the priming dextran infusion (corresponding to the third postmeal hour in groups I and II), the fractional clearances of all dextran fractions remained essentially unchanged from those in the second postprime hour (corresponding to baseline clearances in groups I and II). There was similar constancy of GFR, which averaged $32 \pm 10 \mathrm{ml} / \mathrm{min}$ per $1.73 \mathrm{~m}^{2}$ at both times, and of RPF, which increased only slightly from $211 \pm 70$ to $231 \pm 91$ $\mathrm{ml} / \mathrm{min}$ per $1.73 \mathrm{~m}^{2}(P=\mathrm{NS})$. As may be seen in Table VII, small but insignificant changes in dextran sieving coefficients during the later determination occurred in either direction and were, for the most part, within one standard error of the earlier values. This constancy of the fractional dextran clearance profile during a prolonged fast points to protein ingestion as the proximate cause of the altered glomerular dynamics and sieving behavior observed in group I and II subjects.

\section{Theoretical analysis of GFR determinants}

From the value of plasma protein concentration $(6.2 \pm 0.1 \mathrm{~g} / \mathrm{dl})$ and the filtration fraction, we computed that baseline efferent oncotic pressure in group I subjects was $30 \mathrm{~mm} \mathrm{Hg}$. We then used a model of hindered solute transport through water-filled pores to search for a value of $\Delta \mathrm{P}$ between 31 and $42 \mathrm{~mm} \mathrm{Hg}$ that would, along with observed values of GFR, RPF, $\pi_{\mathrm{a}}$, and dextran sieving coefficients in the 36-44- $\AA$ interval, best represent the glomerular capillary wall as an isoporous membrane $(22,23)$. The sum of chi squares was minimized when $\Delta P$ equaled $34 \mathrm{~mm} \mathrm{Hg}$; the corresponding value for $\mathrm{K}_{f}$ was 12.4 $\mathrm{ml} / \mathrm{min} \cdot \mathrm{min} \mathrm{Hg}$, and for $\mathrm{r}_{0}, 57 \AA$ (Table VIII). Whereas the mathematical model cannot accurately fix the value of $\Delta \mathrm{P}$ within several $\mathrm{mm} \mathrm{Hg}$, the least fit value of $34 \mathrm{~mm} \mathrm{Hg}$ provides a basis for identifying the changes in $\Delta \mathrm{P}$ and membrane parameters that were brought about by ingesting the large, protein-rich meal. We accordingly examined the effect of the test meal to lower, increase, or leave unchanged $\Delta \mathrm{P}$ at this assigned, baseline value (Fig. 2). Our theoretical model predicted postmeal dextran sieving coefficients within one standard error of those actually observed when (along with measured changes in RPF, GFR, and $\pi_{\mathrm{a}}$ ) $\Delta \mathrm{P}$ either remained constant or increased above baseline (Fig. 2, left and middle). By least chi-square analysis, the best fit was obtained when $\Delta \mathrm{P}$ was allowed to increase to $38 \mathrm{~mm} \mathrm{Hg}$ (Table VIII); there was a reciprocal decline from baseline values of $\mathrm{K}_{\mathrm{f}}$ to $8.3 \mathrm{ml}$ /

Table VI. Fractional Dextran Clearance

\begin{tabular}{|c|c|c|c|c|c|c|c|c|c|c|}
\hline Molecular radius $(\dot{A})$ & 36 & 38 & 40 & 42 & 44 & 46 & 48 & 50 & 52 & 54 \\
\hline \multicolumn{11}{|l|}{ Group I } \\
\hline Baseline (mean) & 0.282 & 0.205 & 0.144 & 0.100 & 0.070 & 0.049 & 0.032 & 0.020 & - & - \\
\hline$( \pm S E M)$ & 0.025 & 0.018 & 0.013 & 0.009 & 0.006 & 0.005 & 0.004 & 0.003 & NM & NM \\
\hline Postmeal hour 3 (mean) & 0.142 & 0.111 & 0.086 & 0.064 & 0.046 & 0.033 & 0.022 & 0.016 & - & - \\
\hline$( \pm S E M)$ & 0.025 & 0.013 & 0.008 & 0.005 & 0.000 & 0.003 & 0.003 & 0.002 & NM & NM \\
\hline $\begin{array}{l}P \text { value } \\
\text { Group II }\end{array}$ & \multicolumn{7}{|c|}{ Group II } & NS & - & - \\
\hline Baseline (mean) & 0.295 & 0.206 & 0.142 & 0.098 & 0.067 & 0.046 & 0.032 & 0.023 & 0.017 & 0.009 \\
\hline$( \pm S E M)$ & 0.030 & 0.020 & 0.015 & 0.009 & 0.007 & 0.005 & 0.004 & 0.003 & 0.002 & 0.002 \\
\hline Postmeal hour 3 (mean) & 0.204 & 0.146 & 0.097 & 0.075 & 0.052 & 0.035 & 0.023 & 0.016 & 0.011 & 0.007 \\
\hline$( \pm S E M)$ & 0.039 & 0.027 & 0.016 & 0.011 & 0.008 & 0.005 & 0.004 & 0.003 & 0.002 & 0.002 \\
\hline$P$ value & $<0.005$ & $<0.005$ & $<0.005$ & $<0.001$ & $<0.005$ & $<0.005$ & $<0.005$ & $<0.005$ & $<0.01$ & $<0.05$ \\
\hline
\end{tabular}

NM, not measurable. 
Table VII. Fractional Dextran Clearances During Prolonged Fast in Group III

\begin{tabular}{|c|c|c|c|c|c|c|c|c|c|c|}
\hline Molecular radius $(\stackrel{A}{)})$ & 36 & 38 & 40 & 42 & 44 & 46 & 48 & 50 & 52 & 54 \\
\hline Hour 2 postprime (mean) & 0.234 & 0.165 & 0.114 & 0.079 & 0.054 & 0.036 & 0.025 & 0.017 & 0.012 & 0.007 \\
\hline$( \pm S E M)$ & 0.006 & 0.005 & 0.004 & 0.004 & 0.004 & 0.004 & 0.004 & 0.003 & 0.003 & 0.002 \\
\hline Hour 5 postprime (mean) & 0.224 & 0.152 & 0.106 & 0.075 & 0.052 & 0.036 & 0.026 & 0.019 & 0.014 & 0.010 \\
\hline$( \pm S E M)$ & 0.013 & 0.007 & 0.003 & 0.002 & 0.003 & 0.003 & 0.003 & 0.003 & 0.003 & 0.003 \\
\hline$P$ value & NS & NS & NS & NS & NS & NS & NS & NS & NS & NS \\
\hline
\end{tabular}

$\mathrm{min} \cdot \mathrm{mm} \mathrm{Hg}$ and of $\mathrm{r}_{0}$ to $53.9 \AA$. When $\mathrm{r}_{0}$ was held constant at the baseline value, the observed $13 \%$ increase of RPF and computed $12 \%$ increase of $\Delta \mathrm{P}$ failed to lower the baseline dextran sieving coefficients to within one standard error of those actually observed (Fig. 2, right).

That the decline in postmeal $\mathrm{K}_{\mathrm{f}}$ and $\mathrm{r}_{0}$ predicted by the model from average sieving coefficients represents an actual change in intrinsic glomerular membrane properties is suggested by analyzing the sieving curves of individual subjects in the manner of Fig. 2. At a postmeal $\Delta \mathrm{P}$ of $38 \mathrm{~mm} \mathrm{Hg}, \mathrm{K}_{\mathrm{f}}$ fell significantly from $18 \pm 2.6$ to $8.6 \pm 0.6 \mathrm{ml} / \mathrm{min} \cdot \mathrm{mm} \mathrm{Hg}(P$ $<0.05$ ), whereas $r_{0}$ declined from $56.8 \pm 0.4$ to $52.9 \pm 0.3 \AA$ ( $P$ $<0.01)$. At a constant postmeal $\Delta \mathrm{P}$ of $34 \mathrm{~mm} \mathrm{Hg}$, the predicted decline in $\mathrm{r}_{0}$ to $52.7 \pm 0.3 \AA$ was significant $(P<0.01)$, although the smaller change in $\mathrm{K}_{\mathrm{f}}(13.0 \pm 1.4 \mathrm{ml} / \mathrm{min} \cdot \mathrm{mm} \mathrm{Hg})$ failed to reach statistical significance. Thus, according to this theoretical analysis, ingestion of a large, protein-rich meal by normal subjects appears to simultaneously increase resistance to transmembrane water flow (lower $\mathrm{K}_{\mathrm{f}}$ and $\mathrm{r}_{0}$ ), while enhancing ultrafiltration pressure by elevating RPF and $\Delta P$. The computed elevation of ultrafiltration pressure more than offsets increased resistance to water flow, allowing the GFR to rise.

Despite a computed efferent oncotic pressure of only 27 $\mathrm{mm} \mathrm{Hg}$, the value of $\Delta \mathrm{P}$ at baseline that best fitted an isoporous representation of the glomerular capillary wall in group II patients was again $34 \mathrm{~mm} \mathrm{Hg}$, suggesting that chronic glomerulopathy in these subjects was associated with a state of marked filtration pressure disequilibrium (20). The computed $K_{f}$ was only $31 \%$ of that in group $I$, whereas $r_{0}$ was similar (Table VIII). Applying postmeal values of GFR, RPF, and $\pi_{\mathrm{a}}$ to the isoporous model revealed that variations in $\Delta \mathrm{P}$ from the baseline value of $34 \mathrm{~mm} \mathrm{Hg}$ up to $38 \mathrm{~mm} \mathrm{Hg}$ predicted well the measured postmeal sieving coefficients of dextrans of up to 44- $\AA$ radius (Fig. 3). The least chi-square value was similar whether $\Delta \mathrm{P}$ remained constant or increased after the meal
(Table VIII). In contrast, elevation of $\Delta \mathrm{P}$ above $38 \mathrm{~mm} \mathrm{Hg}$ or depression of $\Delta \mathrm{P}$ below $34 \mathrm{~mm} \mathrm{Hg}$ increased the least chisquare value. Thus, a $33 \%$ increase in RPF alone, or in combination with an increase in $\Delta \mathrm{P}$ of up to $12 \%$, can be invoked to account for the observed depression in group II subjects of the postmeal dextran sieving coefficients (Fig. 3). Corresponding changes in $K_{f}$ are small, depending on whether or not $\Delta P$ increased; a small postmeal reduction in $r_{0}$ from 55.9 to 54.5 $\AA$, by contrast, is independent of any change in $\Delta \mathbf{P}^{\prime}$ (Table VIII). Analysis of individual subjects again revealed the reduction of $r_{0}$ to be significant at either level of $\Delta P$, and of $K_{f}$ to be significant when postmeal $\Delta \mathrm{P}$ equaled $38 \mathrm{~mm} \mathrm{Hg}$. As in group I subjects, therefore, ingesting a protein-rich meal appears to have increased GFR in group II subjects by enhancing ultrafiltration pressure. Whether elevation of $\Delta \mathrm{P}$ contributed to the increase in ultrafiltration pressure, or whether the latter was solely a consequence of a large increase in RPF cannot be determined from our theoretical analysis of transmembrane dextran flux.

Each of the selective perturbations of $\Delta \mathrm{P}$ described above was repeated using a starting value above or below $34 \mathrm{~mm} \mathrm{Hg}$. Whereas the least chi-square analysis of observed and predicted dextran sieving coefficients revealed an inferior fit to those in Table VIII, the results were qualitatively similar. Thus, whereas the actual values of $\Delta \mathbf{P}$ are not known, our theoretical analysis suggests that protein ingestion is followed in normal subjects by an elevation of $\Delta \mathrm{P}$, and in glomerulopathic subjects by an elevation or constancy of $\Delta \mathrm{P}$.

\section{Discussion}

Our findings confirm earlier reports of an effect of a large, protein-rich meal to elevate GFR, both in normal subjects and in those with glomerular disease $(24-26,28,29)$. Our theoretical analysis of a simultaneous depression of transglomerular dextran flux suggests that hyperfiltration is a consequence of a

Table VIII. Glomerular Membrane Parameters

\begin{tabular}{|c|c|c|c|c|c|}
\hline & $\Delta \mathbf{P}$ & $\mathbf{K}_{\boldsymbol{r}}$ & $\mathbf{r}_{0}$ & Chi-square & Figure \\
\hline & $m m H g$ & $\mathrm{ml} / \mathrm{min} \cdot \mathrm{mm} \mathrm{Hg}$ & $A$ & & \\
\hline \multicolumn{6}{|l|}{ Group I } \\
\hline Baseline & 34 & 12.4 & 57.0 & 0.009 & \\
\hline \multirow[t]{3}{*}{ Postmeal h 3} & 34 & 11.9 & 53.9 & 0.096 & $2(l e f t)$ \\
\hline & 38 & 8.3 & 53.9 & 0.074 & 2 (middle) \\
\hline & 38 & 8.3 & 57.0 & 1.482 & 2 (right) \\
\hline \multicolumn{6}{|l|}{ Group II } \\
\hline Baseline & 34 & 3.9 & 55.9 & 0.083 & \\
\hline \multirow[t]{2}{*}{ Postmeal h 3} & 34 & 4.2 & 54.5 & 0.039 & $3(l e f t)$ \\
\hline & 38 & 3.3 & 54.5 & 0.040 & 3 (right) \\
\hline
\end{tabular}



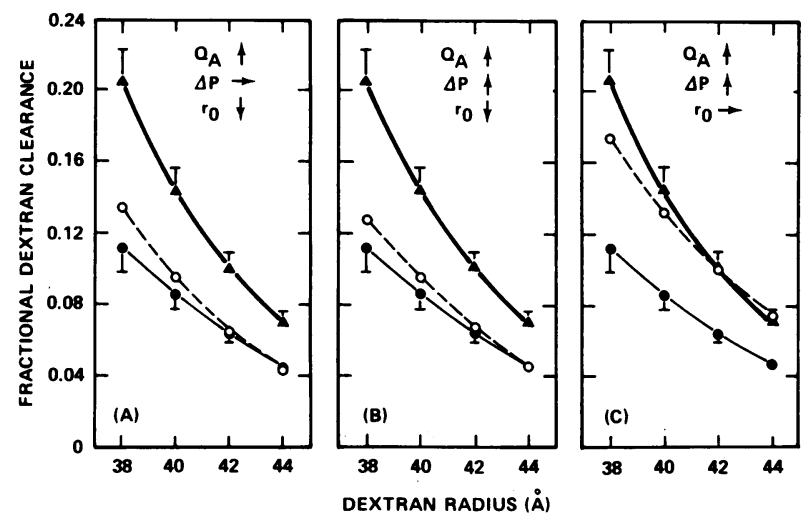

Figure 2. Mean fractional dextran clearances before (solid triangles) and after (closed circles) the protein meal in group I, normal subjects. The open circles are the postmeal fractional dextran clearances predicted by a theoretical model in response to changes in $\operatorname{RPF}\left(Q_{A}\right)$, $\Delta P$, and $r_{0}$ that are indicated at the top of each panel. The best fit between predicted and observed postmeal values is in the middle panel (see Table VIII).

postprandial elevation of ultrafiltration pressure. A combined increase of RPF and $\Delta \mathrm{P}$ is computed to best explain the elevated ultrafiltration pressure in normal subjects (Fig. 2). Although an increase of $\Delta \mathrm{P}$ could also contribute to the observed depression of dextran sieving coefficients in patients with glomerular disease, the findings in this group are equally consistent with an elevation of ultrafiltration pressure due solely to an increase of RPF. A more precise description of postprandial events in the glomerular microcirculation cannot be achieved because of the limited sensitivity of our theoretical analysis. These limitations include possible inaccuracy of an isoporous representation of the glomerular capillary wall, the need for assuming a starting value of $\Delta \mathrm{P}$, and the relative insensitivity of dextran sieving coefficients to increases of $\Delta \mathrm{P}$ above the assumed baseline $(17,22,23)$. Because of these constraints, our analysis should be regarded as providing qualitative information only. It suggests, nevertheless, that protein ingestion leads to a selective or disproportionate lowering of preglomerular vascular resistance. Given that varying levels of protein intake have no influence on Bowman's Space pressure in the rat, our estimates of $\Delta P$ are likely to reflect changes in glomerular capillary perfusion pressure (2). Either constancy of glo-

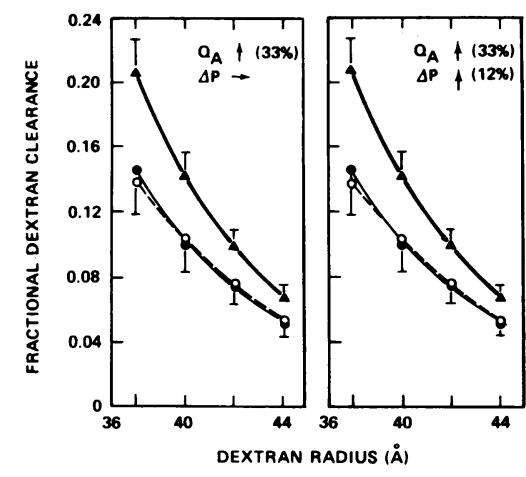

Figure 3. Mean fractional dextran clearances before (solid triangles) and after (closed circles) the protein meal in group II glomerulopathic patients. The open circles are predicted for a postmeal increase in plasma flow $\left(Q_{A}\right)$ that is isolated (left) or occurs in combination with elevation of $\Delta \mathrm{P}($ right $)$. Predicted accompanying changes in $\mathrm{K}_{\mathrm{f}}$ and $\mathrm{r}_{0}$ are listed in Table VIII. merular perfusion pressure at reduced arterial pressure (group II) or elevation of glomerular perfusion pressure at constant arterial pressure (group I) points to a pressure drop from renal artery to glomerular capillaries that is smaller in the postprandial than in the fasting condition.

In accord with the observations of others, the relationship between peak and baseline GFR in Fig. 1 suggests that the magnitude of the postprandial increment in GFR is a function of the extent of initial hypofiltration in those with glomerular disease $(25,26)$. A likely explanation for this phenomenon is the profound lowering of $K_{f}$ in those with advanced glomerular disease suggested by our theoretical analysis (Table VIII). Depression of $K_{f}$ is predicted to lead to a state of marked filtration pressure disequilibrium, and hence to independence of GFR from increases in RPF (30).

Our findings suggest also that a blunted increase of postmeal GFR in those with advanced glomerular disease cannot be attributed to a lack of reserve vasodilator capacity. To the contrary, we observed the PAH clearance to be substantially more enhanced by protein ingestion in patients with glomerular disease than in normal subjects. While this may be due, in theory, to more efficient PAH extraction, the large magnitude of the change together with an attendant depression of dextran sieving coefficients points to a large postprandial increase in true RPF (22): That the microvascular resistors of the renal cortex indeed remain responsive to vasodilator stimuli in glomerulopathic patients is supported moreover by observations in the remnant kidney model in the rat. A strong relationship has been shown to exist between the level of protein intake and the magnitude of the glomerular perfusion rate, even after extensive ablation of renal mass (2).

The precise cause of the renal vasodilatation that occurs in the wake of protein ingestion is unknown. Proposed mechanisms include postabsorptive entry into the circulation of amino acids $(31,32)$, enhanced secretion of glucagon (33), and the release from storage sites in the liver of a vasodilator substance known as glomerulopressin $(34,35)$. While some or all of these vasoactive substances may contribute to a postprandial elevation of glomerular ultrafiltration pressure, we have detected a possible role also for enhanced release and renal activity of angiotensin II and arginine vasopressin, neither of which are ordinarily associated directly with the digestive process. Each has been shown by servo-nulling techniques in the rat to constrict preferentially efferent arterioles, thereby elevating glomerular capillary hydraulic pressure, and hence $\Delta \mathbf{P}$ $(36,37)$. Our computations of constant or elevated $\Delta \mathrm{P}$ at reduced levels of arterial pressure after the test meal are consistent with an enhanced contribution of efferent to total renal vascular resistance in this circumstance. Such relative predominance of efferent arteriolar tone could well be mediated by angiotensin II and arginine vasopressin.

Whereas an effect of protein ingestion to activate the renin-angiotensin system has been demonstrated previously (38), our finding of an additional effect to release arginine vasopressin is novel. That elevated plasma levels of this latter peptide were associated with enhancement of its renal activity is suggested by the observed excretory response. Arginine vasopressin became elevated in plasma after the development of postprandial hyperosmolality (Table III) and was associated with striking urinary concentration (Table II). We note with interest that plasma renin activity in our study became significantly elevated early (hour 1) and arginine vasopressin later 
after the meal (hour 3 ). Together they could have exerted a sustained effect to maintain efferent resistance relatively high, thereby preventing a fall in glomerular perfusion pressure despite a simultaneous decline in overall renal vascular resistance and arterial pressure. It is also worthy of emphasis that both angiotensin II and vasopressin have been shown to lower $K_{f}$, presumably by stimulating mesangial contraction and thus curtailing filtration surface area $(39,40)$. Thus, whereas the nature of substances that lower overall renal vascular resistance remains to be elucidated, the postprandial constancy or elevation of $\Delta \mathrm{P}$ and lowered $\mathrm{K}_{\mathrm{f}}$ suggested by our analysis of depressed transmembrane dextran flux can be readily explained by a combined activation of the renin-angiotensin system and arginine vasopressin.

Although proteinuria in glomerulopathic patients has been found to be heavier at high than low levels of chronic protein consumption (4-6), we have failed to demonstrate an acute effect of protein ingestion on barrier function. Group II, but not group I, subjects of the present study excreted into their urine measurable amounts of dextran of above 50 - $\AA$ radius, reflecting presumably increased permeability of glomeruli in the former to very large macromolecules. In an attempt to define barrier size-selectivity more precisely, we have applied the broader distribution of group II dextran sieving coefficients (Table VI) to a recently described heteroporous model of the glomerular capillary wall (17). This model treats the major portion of the glomerular capillary wall as an isoporous membrane, while incorporating a minor, nonrestrictive membrane component that behaves as a shunt pathway. It reveals $r_{0}$ and $\mathrm{K}_{\mathrm{f}}$ in the major, isoporous membrane component to be similar to the values in Table VIII. The fraction of total filtrate volume, permeating the defective shunt pathway (a useful measure of the extent of impairment of barrier size-selectivity), is computed to be 0.01 before and 0.007 after the meal. The protein-rich fraction of total filtrate volume entering Bowman's space through the shunt pathway remains 0.007 , moreover, whether $\Delta \mathrm{P}$ remains at the hypothetical baseline value of $34 \mathrm{~mm} \mathrm{Hg}$ or increases to $38 \mathrm{~mm} \mathrm{Hg}$.

Because of the relative insensitivity of the refractive index detector employed in the present study, we were unable to determine the urinary concentration of dextrans of above $54-\AA$ radius in group II subjects. Whereas the lack of sieving coefficients for larger dextrans limits the reliability of our computations, the foregoing estimates of the magnitude of the shunt pathway are in keeping with the lowered fractional clearances of both albumin and IgG in the postprandial state. Each of these findings is in sharp contrast to a recent report from our laboratory in which infusion of hyperoncotic albumin acutely impaired barrier size-selectivity in nephrotic subjects, enlarging the shunt pathway and enhancing the fractional clearances of albumin and IgG (12). Ignoring the minimal effect that a minor shunt pathway ( $<1 \%$ of total membrane-pore area) is likely to have on the passage of relatively permeant dextrans (up to $44-\AA \AA$ radius), we have estimated the effect of albumin infusion on $\Delta \mathrm{P}$ in our earlier study using the isoporous membrane approach employed in the current study. We compute that albumin infusion likely increased $\Delta \mathrm{P}$ by $11 \mathrm{~mm} \mathrm{Hg}$, an increase considerably in excess of the $0-4-\mathrm{mm} \mathrm{Hg}$ rise computed for the large protein-rich meal of the present study. That $\Delta \mathrm{P}$ may have to increase by $>4 \mathrm{~mm} \mathrm{Hg}$ to impair barrier size-selectivity is suggested by studies in the rat. Infusion of angiotensin II or renal vein constriction in this species resulted in increased proteinuria and enlargement of a shunt pathway in the size-selective barrier, in association with increases of $\Delta \mathbf{P}$ in the $9-11-\mathrm{mm} \mathrm{Hg}$ range $(41,42)$. Thus, whereas our study has failed to demonstrate an adverse effect of acute protein ingestion on barrier function, it remains possible that chronic consumption of large amounts of protein might impair barrier size-selectivity by causing more marked and/or long-sustained glomerular capillary hypertension.

Without exception, all 24 subjects of the present study were satiated by the large test meal, and most would have refused an additional amount of food. We submit, therefore, that an oral protein load of a magnitude acceptable to patients is unlikely to provide a useful provocative test of the extent of chronic glomerular injury, as has been proposed by others $(25,26)$. In our hands, a postprandial rise of GFR is likely to become blunted only in the final stages of a glomerular disease when baseline GFR is depressed below normal by $>50 \%$. Above this level of injury, a range in which provocative testing is likely to have clinical utility, the increments in GFR and (RPF) after protein ingestion appear to be, if anything, supernormal (Fig. 1, Table IV). Previous studies suggesting the contrary are flawed in our view by the use of creatinine as a filtration marker $(25,26)$. Not only is the tubular secretory contribution to the creatinine clearance enhanced considerably in the presence of glomerular disease (43), but protein ingestion failed to increase this component of the creatinine clearance in the present study. As a result, the creatinine clearance markedly underestimated the postmeal increment in GFR in group II subjects (Table V). Failure of a large protein meal to exacerbate barrier dysfunction reduces still further the likelihood that this perturbation will unmask or magnify an early, and hence treatable, stage of chronic glomerular injury. More promising, we propose, is the use of a large oral protein load to identify either neurohormonal or other possible mediators of glomerular overperfusion. Pharmacologic inhibition of such mediators may prevent glomerular overperfusion, thereby protecting diseased glomeruli against progressive injury.

\section{Acknowledgments}

We wish to thank Janet Cecchino and the Nutrition Service at Stanford University Medical Center for their invaluable assistance in preparing the test meal used in this study.

This study was supported by grant AM-29985 from the National Institutes of Health.

\section{References}

1. Bright, R. 1836. Cases and observations, illustrative of renal disease accompanied by the secretion of albuminous urine. Guy's Hosp. Rep. 1:338-400.

2. Hostetter, T. H., T. W. Meyer, H. G. Rennke, and B. M. Brenner. 1986. Chronic effects of dietary protein in the rat with intact and reduced renal mass. Kidney Int. 30:509-517.

3. Zatz, R., T. W. Meyer, H. G. Rennke, and B. M. Brenner. 1985. Predominance of hemodynamic rather than metabolic factors in the pathogenesis of diabetic glomerulopathy. Proc. Natl. Acad. Sci. USA. 82:5963-5967.

4. Rosenberg, M. E., B. L. Thomas, J. E. Swanson, and T. H Hostetter. 1986. Effect of protein intake on glomerular function in human renal disease. Kidney Int. 29:325. (Abstr.)

5. Kaysen, G. A., J. Gambertoglio, I. Jimenez, H. Jones, and F. N. Hutchison. 1986. Effect of dietary protein intake on albumin homeostasis in nephrotic patients. Kidney Int. 29:572-577. 
6. Rosman, J. B., S. Meijer, W. J. Sluiter, P. M. ter Wee, T. P. M. Piers-Becht, and A. J. M. Donker. 1984. Prospective randomised trial of early dietary protein restriction in chronic renal failure. Lancet. ii: $1291-1296$.

7. Mitch, W. E., M. Walser, T. I. Steinman, S. Hill, S. Zeger, and K. Tungsanga. 1984. The effect of a keto acid-amino acid supplement to a restricted diet on the progression of chronic renal failure. $N$. Engl. J. Med. 311:623-629.

8. Hostetter, T. H., H. R. Rennke, and B. M. Brenner. 1982. The case for intrarenal hypertension in the initiation and progression of diabetic and other glomerulopathies. Am. J. Med. 72:375-380.

9. Rennke, H. G. 1986. Structural alterations associated with glomerular hyperfiltration. In The Progressive Nature of Renal Disease. W. E. Mitch, editor. Churchill-Livingstone, Inc., New York. Vol. 14. 111-131.

10. Davies, D. F., and N. W. Shock. 1950. Age changes in glomerular filtration rate, effective renal plasma flow, and tubular excretory capacity in adult males. J. Clin. Invest. 29:496-507.

11. Aurell, M. 1969. Renal response in man to plasma volume expansion and angiotensin. Scand. J. Clin Invest. 24(Suppl. 2):3-59.

12. Shemesh, O., W. M. Deen, B. M. Brenner, E. McNeely, and B. D. Myers. 1986. Effect of colloid volume expansion on glomerular barrier size-selectivity in humans. Kidney Int. 29:916-923.

13. Bradley, S. E., G. P. Bradley, C. J. Tyson, J. J. Curry, and W. D. Glake. 1950. Renal function in renal disease. Am. J. Med. 9:766-798.

14. Brodwall, E. K. 1960. Renal extraction of PAH in renal disease. Scand. J. Clin. Lab. Invest. 16:12-20.

15. Bergstrom, J., H. Bucht, E. Ek, B. Josephson, H. Sundell, and L. Werko. 1960. The renal extraction of para-aminohippurate in normal persons and in patients with diseased kidneys. Scand. J. Clin. Lab. Invest. 11:361-375.

16. Carghill, W. H. 1948. The measurement of glomerular and tubular plasma flow in the normal and diseased human kidney. J. Clin. Invest. 28:189-192.

17. Deen, W. M., C. R. Bridges, B. M. Brenner, and B. D. Myers. 1985. Heteroporous model of glomerular size-selectivity: application to normal and nephrotic humans. Am. J. Physiol. 249:F374-F389.

18. Bryer-Ash, M., R. A. Ammon, and J. A. Luetscher. 1983. Increased inactive renin in diabetes mellitus without evidence of nephropathy. J. Clin. Endocrinol. \& Metab. 56:557-561.

19. Keil, L. C., and W. B. Severs. 1977. Reduction in plasma vasopressin levels of dehydrated rats following acute stress. Endocrinology. 100:30-38.

20. Chang, R. L. S., W. M. Deen, C. R. Robertson, C. M. Bennett, R. J. Glassock, and B. M. Brenner. 1976. Permselectivity of the glomerular capillary wall. Studies of experimental glomerulonephritis in the rat using neutral dextran. J. Clin. Invest. 57:1272-1280.

21. Chang, R. L. S., I. F. Ueki, J. L. Troy, W. M. Deen, C. R. Robertson, and B. M. Brenner. 1975. Permselectivity of the glomerular capillary wall to macromolecules. II. Experimental studies in rats using neutral dextran. Biophys. J. 15:887-895.

22. Chang, R. L. S., C. R. Robertson, W. M. Deen, and B. M. Brenner. 1975. Permselectivity of the glomerular capillary wall to macromolecules. I. Theoretical considerations. Biophys. J. 15:861-886.

23. Deen, W. M., B. D. Myers, and B. M. Brenner. 1982. The gomerular barrier to macromolecules: theoretical and experimental considerations. In Contemporary Issues in Nephrology: Nephrotic Syndrome. B. Brenner and J. Stein, editors. Churchill-Livingstone, Inc., New York. 1-29.

24. Bosch, J. P., A. Saccaggi, A. Lauer, C. Ronco, M. Belledonne, and S. Glabman. 1983. Renal functional reserve in humans. Effect of protein intake on glomerular filtration rate. Am. J. Med. 75:943-950.

25. Bosch, J. P., A. Lauer, and S. Glabman. 1984. Short-term protein loading in assessment of patients with renal disease. Am. J. Med. 77:873-879.

26. Rodriguez-Iturbe, B., J. Herrera, and R. Garcia. 1985. Response to acute protein load in kidney donors and in apparently normal postacute glomerulonephritis patients: evidence for glomerular hyperfiltration. Lancet ii:461-464.

27. Oken, D. E., B. B. Kirschbaum, and D. M. Landwehr. 1981. Micropuncture studies of the mechanisms of normal and pathologic albuminuria. In Contributions of Nephrology. G. M. Berlyne, editor. S. Karger AG, Basel. 24:1-7.

28. Hostetter, T. H. 1986. Human renal response to a meat meal. Am. J. Physiol. 19:F613-F618.

29. Pullman, T. N., A. S. Alving, R. J. Dern, and M. Landowne. 1954. The influence of dietary protein intake on specific renal functions in normal man. J. Lab. Clin. Med. 44:320-330.

30. Deen, W. M., C. R. Robertson, and B. M. Brenner. 1972. A model of glomerular ultrafiltration in the rat. Am. J. Physiol. 223:1178-1183.

31. Meyer, T. W., I. Ichikawa, R. Zatz, and B. M. Brenner. 1983. The renal hemodynamic response to amino acid infusion in the rat. Trans. Assoc. Am. Physicians. XCVI:76-83.

32. ter Wee, P. M., J. B. Rosman, S. van der Geest, W. J. Sluiter, and A. J. M. Donker. 1986. Renal hemodynamics during separate and combined infusion of amino acids and dopamine. Kidney Int. 29:870-874.

33. Premen, A. J., J. E. Hall, and M. J. Smith, Jr. 1985. Postprandial regulation of renal hemodynamics: role of pancreatic glucagon. Am. J. Physiol. 248:F656-F662.

34. Alvestrand, A., and J. Bergstrom. 1984. Glomerular hyperfiltration after protein ingestion, during glucagon infusion, and in insulin-dependent diabetes is induced by a liver hormone: deficient production of this hormone in hepatic failure causes hepatorenal syndrome. Lancet i:195-197.

35. Premen, A. J. 1985. Importance of the liver during glucagonmediated increases in canine renal hemodynamics. Am. J. Physiol. 249:F319-F322, 1985.

36. Blantz, R. C., K. S. Konnen, and B. J. Tucker. 1976. Angiotensin II effects upon the glomerular microcirculation and ultrafiltration coefficient of the rat. J. Clin. Invest. 57:419-434.

37. Yared, A., V. Kon, and I. Ichikawa. 1985. Mechanism of preservation of glomerular perfusion and filtration during acute extracellular fluid volume depletion. Importance of intrarenal vasopressinprostaglandin interaction for protecting kidneys from constrictor action of vasopressin. J. Clin. Invest. 75:1477-1487.

38. Paller, M. S., and T. S. Hostetter. 1986. Dietary protein increases plasma renin and reduces pressor reactivity to angiotensin II. Am. J. Physiol. 19:F34-F39.

39. Ausiello, D. A., J. J. Kreisberg, C. Roy, and M. J. Karnovsky. 1980. Contraction of cultured rat glomerular mesangial cells after stimulation with angiotensin II and arginine vasopressin. J. Clin. Invest. 65:754-760.

40. Sraer, J. D., J. Sraer, R. Ardaillou, and O. Mimoune. 1974. Evidence for renal glomerular receptors for angiotensin II. Kidney Int. 6:241-246.

41. Yoshioka, T., H. G. Rennke, D. J. Salant, W. M. Deen, and I. Ichikawa. 1986. Hemodynamic alterations modulate the expansion and the glomerular sieving defect in rat membranous glomerulopathy (MGN). Kidney Int. 29:390. (Abstr.)

42. Yoshioka, T., T. Mitarai, V. Kon, W. M. Deen, H. G. Rennke, and I. Ichikawa. Role for angiotensin II in an overt functional proteinuria. Kidney Int. 30:538-545.

43. Shemesh, O., H. Golbetz, J. P. Kriss, and B. D. Myers. 1985. Limitations of creatinine as a filtration marker in glomerulopathic patients. Kidney Int. 28:830-838. 